\title{
The Use of Conjunctions as Grammatical Cohesion in the Speeches of Her Majesty Queen Rania of Jordan
}

Hatmal Odeh Al-Khalidy*

Department of English, AlBaha University, AlBaha, Saudi Arabia

Corresponding Author: Hatmal Odeh Al-Khalidy, E-mail: hatmal88@yahoo.com

\section{ARTICLE INFO}

Article history

Received: March 07, 2018

Accepted: May 12, 2018

Published: September 01, 2018

Volume: 7 Issue: 5

Advance access: July 2018

Conflicts of interest: None

Funding: None

\begin{abstract}
Halliday and Hasan (1976) differentiated between four types of conjunctions namely, additive, causal, temporal and adversative. Thus, conjunctions are words used to combine two sentences, this paper examines the conjunctions in the speeches of Her Majesty Queen Rania of Jordan based on Halliday and Hasan (ibid). The investigator in this current study selected four different speeches which were delivered by Queen Rania in Jordan and USA in the years 2007, 2009, 2011 and 2013. The results show that there are some differences in the frequency of additive, causal, adversative and temporal conjunctions. The study concluded that, additive conjunctions were the most frequent conjunctions followed by adversative conjunctions and then causal conjunctions and finally the least occurrences were for temporal conjunctions.
\end{abstract}

Key words: Additive conjunctions, Adversative Conjunctions, Causal Conjunctions, Temporal Conjunctions, Grammatical Cohesive Devices

\section{INTRODUCTION}

This study entitled the use of conjunctions as grammatical cohesion in the speeches of Her Majesty Queen Rania of Jordan. According to Nunan (1993:5) "discourse is a stretch of language consisting of several sentences which are perceived as being related in some ways". However, Schiffrin, et al. (2001:1), identify discourse as anything "beyond the sentence". That means there are some cohesive devices to hang a text. Salkie (1995) claims that connectives are phrases and words used that connect different parts of a text. Morris and Hirst (1991) state that the concept of patterns of lexical affinity, cohesive harmony and the building blocks of lexical cohesion are lexical semantic relations.

Carter et al. (2005) define conjunction as joining. Furthermore, all aspects of both lexical and grammatical cohesive devices are to link text items together. Crystal (1992:25) defines "Discourse as a continuous stretch of (especially spoken) language larger than a sentence, often constituting a coherent unit such as a sermon, argument, joke, or narrative". According to Cook (1995), novels, short conversation or groans can also be called discourse. After Halliday \& Hasan work on the term cohesion in the year 1976 similarly, some scholars followed them to deal and analyse written and spoken texts, Cook (ibid) remarks that any discourse or cohesive devices include the following seven types: verb form, parallelism, referring expressions, repetition and lexical chains, substitution, ellipsis and conjunction. Moreover, the classification of Salkie (ibid) about cohesive devices is similar to the classification of Carter et al. (ibid), as addition connectives, opposition connectives, cause connectives and time connectives. Al Khalidy (2012).

Dooley and Levinsohn (2001) distinguished between six categories of cohesive devices such as, descriptive expressions alluding to entities mentioned earlier, identity, lexical relations, Morphosyntactic patterns, signals of relations between propositions and intonation patterns. According to Dooley and Levinsohn (ibid.), conjunctions have three different types namely, associatives, additives and developmental markers. Moreover, Winter (1977) classifies the conjunctive role into four levels namely, lexical item within the predicate of the clause, adverbial clause plus nominalisation, adverbial clause as conjunction and single word conjunction.

\section{LITERATURE REVIEW}

Since the introduction of cohesion by Halliday and Hasan (1976) various studies were performed on text analysis in order to analysis either lexical cohesion as word repetition, synonym, antonym, hyponym or grammatical cohesion like references, substitution, ellipsis and conjunctions.

In this regard, Halliday and Hasan (1976:239-40) gave a scheme to distinguish between four categories of conjunctives. These are additive (for example 'and'), causal (for example 'so'), temporal (for example 'then'), and adversative (for example 'yet').

Shoghosho ara (1996) analysed conjunctions as a cohesive device in two levels one is: Persian stories at children and the other level is adults to see the differences in the usage of con- 
junction in such texts. She found that the four kinds of conjunctions are occurred in both levels. Also, statistics showed that the frequency of additive conjunctions were the most occurred types of conjunctions at the different two levels.

El Saj (2012) examined the personal pronouns in Oprah Winfrey hosting Queen Rania of Jordan, she found that the subjects "You" and "I" are the most frequent personal pronouns used in Oprah's utterances than the other personal pronouns.

Ahangar et al (2012) investigated the use of conjunctions as cohesive devices in Iranian sport live radio and TV talks. They concluded that, associative conjunctions were the most productive type of conjunctions, with no any significant differences. However, the application of adversatives, additives and developmental markers showed a meaningful relation in the radio and TV corpus. In addition, the TV corpus exceeded the radio data in the use of these three sub-types. Also, associative conjunctions were the most frequent conjunctions, followed by additive conjunctions.

Hananta and Sukiyaki (2015) analysed the use of cohesion in students' argumentative writings, and found that the conjunction occurrences was $(23.47 \%)$ one of the highest contributors in grammatical coherence after reference. The most frequency was for additive conjunction 198 times, followed by temporal frequency 82 times, causal and adversative 60, 59 times respectively.

Mohammed (2015) studied conjunctions as cohesive devices in the writings of English as second language learners. He came out with the following findings; out of 120 times of conjunctions the students utilize higher rates of extensive elements with 79 which form $66 \%$ in all the texts. Also, he added in spite of their number of occurrences, there are numerous instances of wrong usages.

Ratnasari and Sudartini (2016) studied the use of cohesive devices in the speech of speaking IV students of English education study program of the academic year of 2014. They studied 18 different speeches by 1267 cohesive ties both grammatically and lexically. The grammatical cohesion appeared 832 times or $65.7 \%$ of the total occurrence which consisted of reference 281 times or $22.2 \%$, substitution 6 times or $0.5 \%$, ellipsis 69 times or $5.4 \%$, and conjunction 476 times or $37.6 \%$. The lexical cohesion appeared 435 times or $34.3 \%$ of the total occurrence consisting of reiteration 340 times or $26.8 \%$ and collocation 95 times or $7.5 \%$.

\section{METHODOLOGY}

Queen Rania is not only an effective communicator but also an eloquent speaker. In other words, Her speeches on crucial issues have been very well acclaimed by the Arabs as well as by the international audience. Regarding data collection, the following speeches have been taken as the sample from many speeches delivered by Her Majesty. These four speeches were used especially for the purpose of the numerical analysis of different conjunctions as grammatical cohesion used by the Queen in terms of additives, adversatives, causal and temporal. Therefore, the speeches were selected randomly and this study employed a combination of descriptive and quantitative method by its nature. Accordingly, this section is devoted for the analysis of the use of conjunctions as grammatical cohesion in the speeches of the Queen.

\section{The Speeches of Her Majesty}

The speeches are arranged chronologically and the place of the speech is followed by the year of the speech within brackets. Then the occasion for the delivering the speech has also been given.

I- USA, (2007)

Speech by Her Majesty Queen Rania at the women's conference in California

II- USA, Yale University (2009)

Speech by Her Majesty Queen Rania at Yale University

III- USA, Harvard (2011)

Speech by Her Majesty Queen Rania at John F. Kennedy Forum

IV- Jordan, (2013)

Queen Rania speaks at the international academy on graduation ceremony in Amman

From Table 3.1 it can be found that the conjunction and has been more frequently used in the speeches (253) times followed by the conjunction or (37) times.

Having a look at the Table 3.2, one can observe that the adversative conjunction but occurs (51) times in the speeches than the other two adversative conjunctions analysed, and the least of occurring adversative was however.

A glance at Table 3.3 shall reveal that the Queen has used because (28) times, so (10) times, since (2) times.

From the Table 3.4 we can conclude that the use of temporal conjunctions in the four speeches of the Queen. Her Majesty has used the temporal conjunctions then (5) times, next (4) times whereas the conjunction subsequently did not occur.

\section{RESULTS AND DISCUSSION}

The following section illustrates the results of the main four types of conjunctions and their sub-types namely, additive

Table 3.1 The frequency of additive conjunctions

\begin{tabular}{ccc}
\hline And & Or & Total \\
\hline 253 & 37 & 290 \\
\hline
\end{tabular}

Table 3.2 The frequency of adversative conjunctions

\begin{tabular}{cccc}
\hline But & Yet & However & Total \\
\hline 51 & 7 & 3 & 61 \\
\hline
\end{tabular}

Table 3.3 The frequency of causal conjunctions

\begin{tabular}{llcc}
\hline Because & So & Since & Total \\
\hline 28 & 10 & 2 & 40 \\
\hline
\end{tabular}

Table 3.4 The frequency of temporal conjunctions

\begin{tabular}{lcc}
\hline Then & Next & Total \\
\hline 5 & 4 & 9 \\
\hline
\end{tabular}


conjunctions, adversative conjunctions, causal conjunctions and temporal conjunctions.

\section{Analysis of Additive Conjunctions (Used to Connect by Adding to the Presupposed Item)}

The main purpose here is to analyse the additive conjunctions that are found in the speeches of Her Majesty (and, or).

From the Figure 4.1 it can be concluded that as for as the use of additive conjunctions are concerned, Her Majesty has used more additive conjunctions in Her speeches (290) times than the adversative conjunctions, causal conjunctions and temporal conjunctions. As (253) times for the additive conjunction and with (37) times for the additive or. Here are examples from the data:

(1) The decades have brought what feels like an endless parade of starts and stalemates missed opportunities shattered hopes and diminishing returns (USA, 2009).

(2) To show our tremendous respect and admiration for the difficult job they are doing (USA, 2007).

(3) I do not want you to see your future or just look at the world the way it is I want you to imagine it, see it as it should be (Jordan, 2013).

(4) Some caricatures are not nearly as easy to laugh off Arabs or Muslims as terrorists for example and Americans as people (USA, 2007).

\section{Analysis of Adversative Conjunctions (Refer to Contrary to Expectation)}

The purpose here is to see the adversative conjunctions that are found in the speeches of Her Majesty (but, yet and however).

By observing Figure 4.2 on the use of adversative conjunctions shows that, out of 61 times (the total number of adversative conjunctions in the speeches), the Queen uses but (51) times yet (7) times and the least occurrences was for however (3) times. Here are examples from the data:

(5) They appealed not only to logic but to simple human values like acceptance, love and crucially each of them (USA, 2011).

(6) We all know the story of Cinderella but real life is not a fairy tale (USA, 2007).

(7) They have not actually experienced and yet many choose to remain comfortably within the bounds of their own experience (USA, 2009).

(8) Andrews Kings College the London School of Economics and the list go on yet we must recognize that your success has many roots (Jordan, 2013)

(9) The family unit eastern eyes however see Arab women taking an even greater role in society as doctors, lawyers, teachers, journalists, politicians and entrepreneurs (USA, 2011).

(10) However we pray, we respond to human suffering as human beings but we must do more than find unity in grief (USA, 2007)

\section{Analysis of causal conjunctions (explain about purpose, reason and result)}

The purpose here is to focus on the causal conjunctions that are used by Her Majesty (because, so and since).

Figure 4.3 indicates that the occurrence of causal conjunctions in speeches of Her Majesty, the conjunction because (28) times, followed by the conjunction so (10) times, whereas the least number of occurrence was for the conjunction since (2) times only. Here are examples from the data:

(11) Fall hopelessly in love with what you choose to do and be good at it in fact be great because good is just not good enough anymore (Jordan, 2013).

(12) Somewhere within my stories you will hear something that sounds familiar because I am convinced that we are all much more alike than we are different (USA, 2007).

(13) Good is just not good enough anymore so do not let other people's choices dictate yours do not follow their map

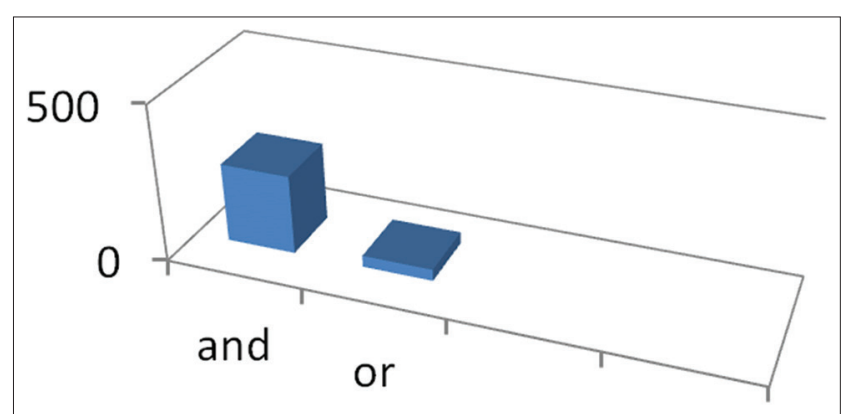

Figure 4.1.Uses of additive conjunctions in the speeches of Her Majesty

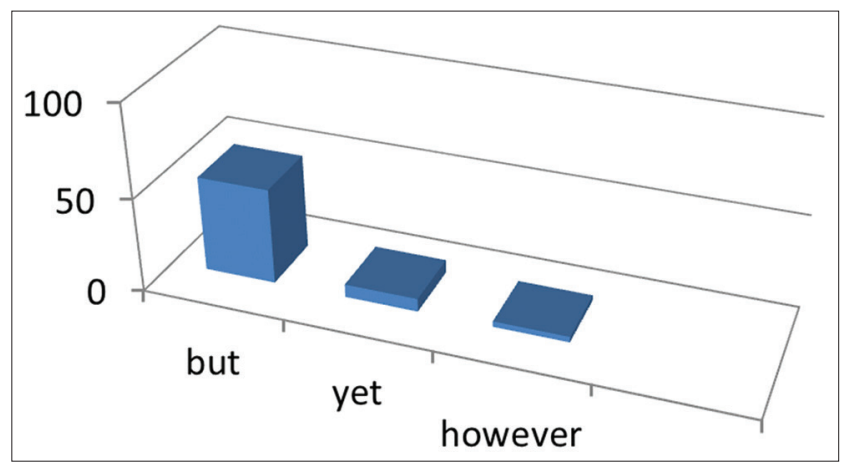

Figure 4.2. Uses of adversative conjunctions in the speeches of Her Majesty

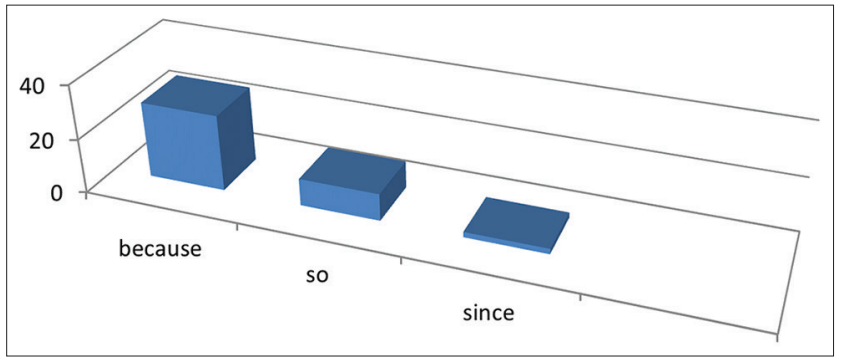

Figure 4.3.Uses of causal conjunctions in the speeches of Her Majesty 
sketch your own be passionate (Jordan, 2013).

(14) The destination is uncertain all you need are your minds and your hearts to help you on your way so remember life is an adventure enjoy the excitement of uncertainty (Jordan, 2013).

(15) People have suffered for decades and whose lives have become even worse since the US invasion and occupation through the Arab window the American presence is unwanted unwelcome and unjust (USA, 2011).

(16) Especially with regard to the Israeli-Palestinian conflict and I am guessing since you made the time to be here today (USA, 2009).

\section{Analysis of Temporal Conjunctions (Connect by Signalling Sequence or Time)}

The analysis here in this part is to focus on the temporal conjunctions that are used by Queen Rania (then and next).

From the Figure 4.4 one can sum up that the use of temporal conjunctions by Her Majesty. The Queen has used temporal conjunctions in her speeches (9) times. Here are examples from the data:

(17) Be dreamers, be bold then work hard and make it happen that means you also have to be brave what if you tripped in the dark what if you find yourself lost do not panic (Jordan, 2013).

(18) My husband replied if I start to think that I am a king then I have got a problem (USA, 2011).

(19) How will you navigate the next phase of your life's journey (Jordan, 2013).

(20) You start with topping the $11^{\text {th }}$ graders to recommend they get to Beyonce as next year's speaker (Jordan, 2013).

Finally, the present study had compared the utilization of conjunctions as grammatical cohesion in the speeches of Her Majesty Queen Rania of Jordan. The research findings have highlighted an important function of conjunctions in the

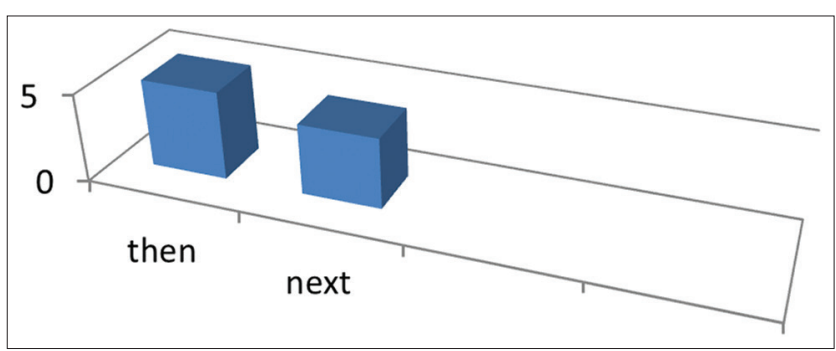

Figure 4.4. Uses of temporal conjunctions in the speeches of Her Majesty

Table 4.5 Overall conjunctions in the speeches

\begin{tabular}{lccc}
\hline Type & & Total occurrences & Percentage \\
\hline Additive & 290 & $72.5 \%$ \\
Adversative & 61 & $15.2 \%$ \\
Causal & 40 & $10 \%$ \\
Temporal & 9 & $2.2 \%$ \\
Total & 400 & $99.9 \%$ \\
\hline
\end{tabular}

speeches of Her Majesty: The study clarified that additive conjunctions are the most frequently used ones 290 times, followed by adversative conjunctions with 61 times, causal conjunctions 40 times and the least occurrences were for temporal conjunctions with 9 times.

Based on data analysis, it is found that the most frequent additive conjunction was for the connective 'and' whereas the less frequently used connective was 'or'. Regarding the use of adversative conjunctions in the speeches, the most occurrences were for however. As for the use of causal conjunctions by Her Majesty, they occurred 61 times for the three connectives because, so and since, 28,10,2 times respectively. Her Majesty has used more or less equal times for the usage of temporal conjunctions 5 times for then and 4 times for the usage of next.

\section{CONCLUSION}

The language of politicians is aimed at convincing the audiences. The words are selected carefully in order to persuade the audience towards their message. The selection of words, sentences and expressions are very important to be analysed by scholars in order to observe cohesion and coherence in speeches of political leaders. The present study had analysed Her Majesty's speeches with reference to conjunctions and their subtypes (additive, adversative, causal and temporal). The research sample was extracted from four different local and international speeches of Her Majesty. Therefore, based on data analysis, It is worth mentioning that additive conjunctions were noted as the most frequently used by Queen Rania followed by adversatives and then causal whereas temporal conjunctions were the least occurred ones. The Queen used the additive conjunctions 290 times as $87.2 \%$ for and with $12.8 \%$ for or.

Her Majesty utilized 61 times as the total number of usages of adversatives as but $83.6 \%$, yet $11.4 \%$ and the least occurrences were for however $4.9 \%$. Next to adversatives were causal conjunctions 40 times out of which 28 times for because $70 \%, 10$ times for so $25 \%$ and two times only for since $5 \%$. The use of then and next as temporal conjunctions were negligible as 9 times out of the total number of usages 400 times. Of the ten conjunctions and, or, but, yet, however, so, because, since, then and next studied by the researcher, the most frequently used conjunction by Queen Rania in Her speeches was and 253 times in Her two levels of speeches and the least occurred conjunctions were since, however, next, and then 2, 3, 4, 5 times respectively.

\section{REFERENCES}

Ahangar, A., Taki, G., \& Rahimi, M. (2012). The use of conjunctions as cohesive devices in Iranian sport live radio and TV talks. SKASE Journal of Theoretical Linguistics. 9 (2), pp. 56-72.

Al-Khalidy, H. (2012). Discourse Analysis of the political speeches of His Majesty King Abdullah II of Jordan. Unpublished Ph.D. Thesis: Mysore University.

Carter, R., Goddard, A., Reah, D., Sanger, K., \& Bowring, M. (2005).Working with texts: A core introduction to language analysis ( $2^{\text {nd }}$ ed.). London: Rutledge.

Cook, G. (1990). Discourse. Oxford: OUP. 
Crystal, D. (1992). Introducing Linguistics. Harlow: Penguin.

Dooley, R, A., \& Levinsohn, S, H. (2001). Analyzing discourse: A manual of basic concepts. Dallas: SIL International.

El Saj, H. (2012). Discourse Analysis: Personal Pronouns in Oprah Winfrey Hosting Queen Rania of Jordan. International Journal of Social Science and Humanity. Lebanon. 2 (6), pp. $529-532$.

Halliday, M., \& Hasan, R. (1976). Cohesion in English. London: Longman.

Hananta, N., \& Sukyadi, D. (2015).The Use of Cohesion in Students' Argumentative Writings. Indonesia University of Education. 2 (1), pp. $37-65$.

McCarthy, M. (1991). Discourse Analysis for Language Teachers. Cambridge University Press: Cambridge.

Mohammed, A. (2015). Conjunctions as Cohesive Devices in the Writings of English as Second Language Learners. Procedia - Social and Behavioral Sciences. Bauchi State University: Gadau, Nigeria. (208), pp.74 - 81.
Morris, J., \& Hirst, G. (1991). The subjectivity of Lexical cohesion in text, Computational Linguistics. University of Toronto, Canada. 17 (1), pp. 21-48.

Nunan, D. (1993). Introducing Discourse Analysis. London: Penguin English.

Ratnasari, D., \& Sudartini, S. (2016).The Use of Cohesive Devices in the Speech of Speaking IV Students of English Education Study Program of the Academic Year of 2014. Yogyakarta State University. Indonesia.

Salkie, R. (1995). Text and Discourse analysis, London. Rutledge.

Schiffrin, D., Tannen, D., \& Hamilton, H. E. (Eds). (2001). The Handbook of Discourse Analysis. Malden: Blackwell Publishers Inc.

Shoghosho ara, L. (1996). The analysis of cohesion relations in adults and children 's stories. Unpublished M.A. Dissertation: Tehran University.

Winter, E. O. (1977). A clause- relational approach to English Texts: a study of some predictive lexical items in written discourse, Instructional science. Amsterdam. 6 (1), pp. 1-92. 